\title{
A Coherent Life Cycle Assessment of a Range of Lightweighting Strategies for Compact Vehicles
}

\author{
Marco Raugei*, Denise Morrey, Allan Hutchinson, Patricia Winfield \\ Faculty of Technology, Design and Environment, Oxford Brookes University, \\ Wheatley Campus, Wheatley OX33 1HX, UK \\ *Corresponding author. E-mail: marco.raugei@brookes.ac.uk
}

\section{ABSTRACT}

A complete and fully consistent LCA-based comparison of a range of lightweighting options for compact passenger vehicles is presented and discussed, using advanced lightweight materials (Al, Mg and carbon fibre composites), and including all life cycle stages and a number of alternative end-of-life scenarios. Results underline the importance of expanding the analysis beyond the use phase, and point to maximum achievable reductions of environmental impact of approximately $7 \%$ in most impact categories. In particular, lightweighting strategies based on the use of aluminium were found to be the most robust and consistent in terms of reducing the environmental impacts (with the notable exception of a relatively high potential toxicity). The benefits of using magnesium instead appear to be less clear-cut, and strongly depend on achieving the complete phase-out of $\mathrm{SF}_{6}$ in the metal production process, as well as the establishment of a separate close-loop recycling scheme. Finally, the use of carbon fibre composites leads to similar environmental benefits to those achieved by using Al, albeit generally at a higher economic cost. 


\section{INTRODUCTION}

The automotive industry's current position as a significant contributor to global environmental impact, and more specifically greenhouse gas emissions, is clearly unsustainable, and also less and less acceptable to modern environmentally aware societies. In the United Kingdom, for instance, transportation currently accounts for approximately a quarter of the total direct greenhouse gas emissions in the country (UK government, 2014a). Cars have also been shown to be the most carbon-intensive means of personal transportation on land (Borken-Kleefeld et al., 2013). Besides turning to more efficient and environmentally friendly power train options, one of the most effective strategies to cut down on a whole range of environmental impacts associated to the use phase of a vehicle is, unquestionably, to reduce its kerb mass (US-DoE, 2015; Koffler and RhodeBrandenburger, 2010), and indeed a range of lightweighting strategies are currently being considered and tested by many car manufacturers in Europe and elsewhere (e.g. Audi, 2013; BMW, 2015; Ford, 2014; JLR, 2015). However, the production and processing of lightweight material parts often entails higher specific environmental burdens compared to the predominantly steel parts that they replace (Liu and Müller, 2012; IMA, 2013; Das, 2011), and it is therefore essential to expand the scope of the analysis beyond the use phase and include all other stages of a vehicle's life cycle, lest the advantages afforded by vehicle lightweighting be overestimated. Life cycle assessment (LCA) is thus arguably the most appropriate approach for the evaluation of the overall environmental consequences of vehicle improvement strategies based on the use of advanced lightweight materials.

A large number of individual LCA studies are available in the literature in which specific lightweighting strategies have been discussed and analysed (EAA, 2013; Das, 2014; Tharumarajah and Koltum, 2007; Du et al., 2010; Duflou et al., 2009; Koffler, 2014; Schmidt et al., 2004; Mayyas et al., 2012; Kim et al., 2010). However, the lack of consistency in terms of scope, assumptions, boundary conditions and impact metrics render any comparison across different studies fraught with difficulty and potentially misleading. An ex-post 
harmonization effort is undoubtedly helpful in removing unnecessary inconsistencies and allowing some general inferences to be made (Kim and Wallington, 2013); yet, ultimately, complete and fully coherent comparisons of alternative lightweighting strategies are still few and far between. This paper aims to fill this void by discussing the results of a new comparative LCA of a range of vehicle lightweighting options using advanced lightweight materials (aluminium, magnesium and carbon fibre reinforced polymers), including all life cycle stages of the entire vehicle and considering alternative end-of-life (EoL) scenarios. All options and scenarios are based on the same fundamental model and share the same underlying assumptions and system boundary, thereby ensuring strict methodological consistency across the board and allowing robust and scientifically sound conclusions to be drawn.

\section{MATERIALS AND METHODS}

This section includes: a concise introduction to the adopted methodology; the illustration of the unified LCA model underlying the full range of analysed lightweighting strategies, including a discussion of all relevant assumptions and key parameters; and a detailed examination of the lightweighting strategies themselves.

\subsection{A UNIFIED LCA MODEL OF A COMPACT VEHICLE}

From its first official definition by the Society of Environmental Toxicology and Chemistry (SETAC) in 1993 (Consoli et al., 1993), and through its subsequent standardisation by the International Organization for Standardization (ISO, 2006a,b), the core principle of LCA has always been that the environmental impact of a product or system must be assessed including all stages of its service life, 'from the cradle to the grave', since each of those stages entails some degree of environmental impact, both in terms of the depletion of primary resources and of the adverse effects of the associated emissions. Additionally, in many cases, as indeed that of the systems under study here, it is important to extend the 
concept even further, to explicitly include the 'environmental credits' due to those material or energy flows which may be recovered and put to new use after the product or system is decommissioned (leading to the common phrase 'from the cradle to the cradle'). LCA has quickly become the method of choice in an ever-increasing range of sectors and applications, and its use has even been endorsed by likening it to a form of "environmental intelligence" (Schnoor, 2009).

All the alternative scenarios analysed here share the same functional unit, namely the full life cycle of a generalised $C$ segment car (the commonest type of passenger vehicle in Europe (ICCT, 2013)), including raw material sourcing and processing, vehicle manufacturing, use phase, vehicle maintenance and end-of-life decommissioning.

LCA terminology refers to those processes which "are under direct control of the producer of the good or operator of the service, or user of the good or where he has decisive influence" as being in the 'foreground' (JRC, 2010), while all other processes are considered to be in the 'background'. Our analysis is framed as a purely attributional (as opposed to consequential) LCA, and as such it is concerned with analysing and comparing the alternative systems under the 'static' assumption that their life cycle does not significantly alter the larger system into which they are embedded (including the supply chains of their material and energy inputs). In other words, the analysis assumes a constant background system in terms of all material supply chains, including e.g. the electricity mix(es) used for material production and vehicle manufacturing, and of the EoL treatment technologies (incineration, landfilling and recycling).

All background processes were modelled on the basis of those provided in the Ecoinvent 2.2 life cycle inventory (LCI) database (Ecoinvent, 2010), with the sole exceptions of thermal magnesium production and carbon fibre (CF) production, which were not available in Ecoinvent and for which we resorted to using the GaBi database instead (Thinkstep, 2015a). Whenever required or appropriate, such background models were modified or adapted, based on up-to-date literature information (specifically, all foreground electricity was 
assumed to be sourced from the current UK supply mix (UK government, 2014b); more details are provided below for other specific processes).

From an operational point of view, the entire analysis was performed with the commercial software package GaBi Professional v. 6.2 (Thinkstep, 2015b).

\subsubsection{Manufacturing phase}

A specific goal of the study was to identify which lightweighting strategies for the vehicle's body and chassis could afford the largest reductions in life-cycle environmental impacts. Accordingly, the bill of materials for the foreground manufacturing of the all-steel benchmark vehicle's body was informed by an advanced vehicle concept being developed by Coventry University in the UK, and deemed to be representative of the current state of the art in terms of mass optimisation for a $\mathrm{C}$ segment passenger car. The rationale for this was that in order to correctly estimate the incremental lightweighting benefits afforded by the adoption of advanced materials in a vehicle's body, the latter should already be optimised to the maximum possible extent in the all-steel benchmark.

The analysis of the vehicle's remaining sub-assemblies, namely the power train, electrical system and trim, was then suitably streamlined by modelling such parts with a lower level of granularity, and was informed by a range of reputable literature sources (Ecoinvent, 2010; Eckstein et al., 2011).

Secondary weight reductions, i.e. those theoretically made possible by downsizing other vehicle components (e.g. engine, brakes, fuel tank, etc.) thanks to the increased efficiency achieved by the aforementioned primary lightweighting, were not considered in this analysis because of the difficulty in quantifying them, as attested by the lack of agreement in the literature (Gaines and Cuenca, 2002; Wohlecker, 2007). Instead, the same low-displacement internal combustion engine (ICE) was used across all scenarios (a 44kW Volkswagen petrol engine used in the 2014 production Polo and Golf models), and the required power train 
adaptation to ensure constant driving performance in all scenarios was assumed to occur by means of gear ratio extension.

\subsubsection{Use phase}

The use phase was modelled assuming a typical service life of $150,000 \mathrm{~km}$ and the New European Driving Cycle (NEDC), for which a detailed fuel consumption model was available (Koffler and Rhode-Brandenburger, 2010). The overall reduction in mass-induced fuel consumption corresponding to each lightweighting strategy over the full life cycle of the vehicle $\left(\Delta_{\mathrm{i}}\right)$ was calculated as:

$\Delta_{\mathrm{i}}=\left(\mathrm{M}_{\mathrm{Li}}-\mathrm{M}_{\mathrm{B}}\right) \cdot \mathrm{W}_{\mathrm{M}} \cdot \eta \cdot \mathrm{d} \cdot \mathrm{D} \cdot \mathrm{g} \cdot \mathrm{G} \quad[\mathrm{kg}]$

where:

$\mathrm{M}_{\mathrm{Li}}=$ vehicle mass under lightweighting strategy $\mathrm{i}[\mathrm{t}]$

$\mathrm{M}_{\mathrm{B}}=$ benchmark vehicle mass $=1.1[\mathrm{t}]$

$\mathrm{W}_{\mathrm{M}}=$ vehicle's mass-induced energy demand in NEDC $=0.195[\mathrm{MJ} /(\mathrm{t} \cdot \mathrm{km})]($ Koffler and Rhode-Brandenburger, 2010)

$\eta=$ average differential efficiency of petrol internal combustion engines $=0.0733[\mathrm{~L} / \mathrm{MJ}]$ (Rhode-Brandenburger, 1996)

$\mathrm{d}=$ fuel density $=0.75[\mathrm{~kg} / \mathrm{L}]$

$\mathrm{D}=$ total distance travelled $=150,000[\mathrm{~km}]$

$g=$ correction factor to account for energy loss in gearbox $=1.02$

$\mathrm{G}=$ correction factor to account for gear ratio adaptation $=2.0$ (Rhode-Brandenburger and Obernolte, 2008) 
The total combined NEDC fuel consumption of the all-steel benchmark vehicle $\left(F_{B}\right)$ was assumed to be equal to that of the Volkswagen Polo mkV using the same engine and weighing approximately the same $(1,100 \mathrm{~kg}$ kerb mass $)$, i.e. $F_{B}=6.0 \mathrm{~L} / 100 \mathrm{~km}$. The overall fuel consumption corresponding to each lightweighting strategy $\left(F_{L i}\right)$ was then calculated as:

$$
F_{L i}=\left(F_{B}^{*} d * D / 100\right)+\Delta_{i} \quad[k g]
$$

The NEDC has been criticised as being optimistic, as many drivers reportedly struggle to achieve the same fuel consumption performance in real driving conditions; the difference between official NEDC-based consumption figures and real-world ones has been reported as being as high as $21 \%$ by one reputable study (Mock et al., 2012). On the other hand, though, a comparative study on the modelled fuel consumption of manual transmission C segment petrol cars under NEDC conditions vs. the newly proposed (and supposedly more realistic) Worldwide Harmonized Light Vehicles Test Procedure (WLTP) produced 10\% lower fuel consumption and $\mathrm{CO}_{2}$ emissions results for the latter (Mock et al., 2014)

Given the resulting uncertainty on the use phase part of the LCA model, a sensitivity analysis was performed by varying the two parameters directly dependent on the choice of driving cycle, namely $F_{B}$ and $W_{M}$, between $-10 \%$ and $+20 \%$.

The emissions of tailpipe pollutants were modelled according to the vetted and generally well-regarded Ecoinvent process "Operation, passenger car, petrol, EURO 5", which takes into account the fuel consumed and distance travelled.

\subsubsection{Maintenance}

Vehicle maintenance was assumed to consist of tyre changes every $30,000 \mathrm{~km}$, regular check-ups every $30,000 \mathrm{~km}$ (entailing one change of lubricants per check-up and the scheduled replacement of brake pads and $5 \%$ of worn-out trim), one battery replacement at 
$100,000 \mathrm{~km}$, and $10 \%$ outer body panel replacement due to impact damage over the full lifetime of the vehicle.

\subsubsection{End-of-life phase}

EoL treatment of the vehicle's steel parts was modelled to reflect current legislation in Europe for end-of-life vehicles, namely $85 \%$ (open-loop) recycling and $15 \%$ landfilling (Directive 2000/53/EC). Treatment of the lightweight material parts is scenario-dependent and is discussed in more detail in Section 2.2. EoL treatment of all remaining vehicle components (battery, electrical system, tyres, glazing, trim) was modelled equally across all scenarios, again reflecting standard practice: open-loop recycling for glass and batteries, incineration for tyres, $75 \%$ open-loop recycling for Al alloy engine and wheels (Aluminium Federation, 2013) and landfilling for all other parts.

The calculation of the environmental credits ensuing from end-of-life material recycling and energy recovery was performed on the basis of the average mix of the technologies that are actually displaced, which is recommended as the 'safest' and most recommendable assumption in attributional LCAs (on the contrary, marginal substitution is arguably more appropriate in consequential LCAs (Ecometrica, 2008)). Further discussion of this interesting methodological aspect is beyond the scope of the present paper, and is provided elsewhere (Bala Gala et al., 2015). All environmental credits are presented separately for full transparency.

\section{2 LIGHTWEIGHTING STRATEGIES}

The following lightweighting strategies were considered and analysed:

1. all-aluminium body and selected chassis parts;

2. all-magnesium body and selected chassis parts; 
3. aluminium beams, pillars, body in white (BIW) structural components and selected chassis parts, and Carbon Fibre Reinforced Polymer (CFRP) floor-pan, closures and exterior body panels;

4. magnesium beams, pillars, BIW structural components and selected chassis parts, and CFRP floor-pan, closures and exterior body panels.

The assumed mass reductions for the lightweight parts relative to their steel counterparts were as follows: $-50 \%$ for $\mathrm{Al}$ (EAA, 2013), $-60 \%$ for Mg (IMA, 2013; Tharumarajah and Koltum, 2007), and $-70 \%$ for CFRP (Suzuki and Takashi, 2005). The total mass reductions achieved under the four lightweighting strategies were: $-175 \mathrm{~kg}$ (strategy $\mathrm{n} .1$ ); $-214 \mathrm{~kg}$ (strategy n. 2); -210 kg (strategy n. 3); and -232 kg (strategy n. 4). A detailed list of the body and chassis parts and their masses is provided in the Supplementary Information (available via the Internet at: http://www.sciencedirect.com).

Incidentally, we refrained from including a further possible lightweighting strategy based on the use of high-strength steel (HSS) in lieu of conventional mild steel because "given the similar densities of HSS and mild steel, achieving intensive lightweighting through HSS requires significant reliance on secondary lightweighting enabled by primary mass reductions" (Kim et al., 2010). As explained in section 2.1.1, the quantification of such secondary lightweighting is difficult and controversial.

\subsubsection{Strategy n. 1 (Al parts)}

All aluminium parts were assumed to be made of primary (virgin) $\mathrm{Al}$, the production of which was modelled using Ecoinvent's processes for bauxite ore extraction and delivery, alumina production (Bayer process), and its subsequent electro-reduction (Hall-Héroult process). The electricity mixtures used in such models reflect those used in the countries providing the world supply mix of the respective commodities: primarily Australia, Guinea and Jamaica for bauxite, and Australia, the USA and Europe for alumina; most Hall-Héroult plants are instead located in areas where comparatively inexpensive electricity is available, 
most of which is produced by hydro (53\%), nuclear (15\%) and hard coal $(20 \%)$ (Classen et al., 2009).

A sensitivity analysis of the dependence of the results on the EoL treatment of the lightweight Al body and chassis parts was performed by defining two extreme scenarios, respectively referred to as 'pessimistic' and 'optimistic'. In the former scenario the Al parts are $75 \%$ open-loop recycled and $25 \%$ landfilled (the current sector-specific average (Aluminium Federation, 2013)), where open-loop recycling implies replacement of the current mix of primary (virgin) and secondary (recycled) Al. In the latter scenario, instead, the Al parts are assumed to be $90 \%$ close-loop recycled, which implies the $1: 1$ replacement of virgin Al. This corresponds to assuming that, with the increased use of high-quality wrought aluminium alloys in car bodies, the separate collection of high-grade and comparatively 'pure' Al scraps from cars would become economically viable (IAI, 2009).

\subsubsection{Strategy $\mathrm{n} .2$ (Mg parts)}

Mg production has been shifting more and more to China, and today approximately $88 \%$ of global production takes place there (USGS, 2014), almost exclusively via the thermal (Pidgeon) process (IMA, 2013; Gossan Resources, 2012; Du et a., 2010), and using coal as the primary energy source both directly as a fuel and indirectly for the electricity supply mix (US-EIA, 2014). The Ecoinvent LCl database lacks a model for thermal Mg production, and so in this case we used the $\mathrm{GaBi} \mathrm{LCl}$ database model for Chinese Mg production instead, which assumes a mix of $75 \%$ 'standard' and $25 \%$ 'new/green' Pidgeon processes, with coal as the main energy source for both (Thinkstep, 2015a).

All Mg parts were then assumed to be made of the common AZ91D alloy produced in Europe, and the alloying process was modelled in Ecoinvent (Classen et al., 2009) using the current ENTSO-E (formerly UCTE) electricity grid mix.

The issue of sulphur hexafluoride $\left(\mathrm{SF}_{6}\right)$ use as a corrosion protection ('cover') gas in magnesium smelting and casting merits special attention and discussion. $\mathrm{SF}_{6}$ is the most 
potent greenhouse gas (GHG) of all those defined under the Kyoto Protocol, with an estimated atmospheric lifetime of 3,200 years and a 100-year global warming potential (GWP) of 23,900 relative to $\mathrm{CO}_{2}$ (IPCC, 2007).

In Europe, $\mathrm{SF}_{6}$ is strictly regulated, and its use for die casting has been banned since $1^{\text {st }}$ January 2008 (Regulation (EC) No 842/2006). No similar ban is yet in place in any other parts of the world (including e.g. the USA); however, alternative strategies for corrosion protection are used in many modern magnesium processing plants worldwide (Gossan Resources, 2012; DG Environment, 2009), often employing other cover gases like $\mathrm{SO}_{2}$ (which, however, is sub-optimal since it may negatively affect the quality of the metal and corrode steel equipment (US-EPA, 2014)) or R134a (itself also a GHG, but less potent than $\mathrm{SF}_{6}$ ). If $\mathrm{SF}_{6}$ is used as a cover gas, the amount that ends up being emitted depends on the quantity used and on the technology deployed to reduce the emissions, and may vary over two orders of magnitude (Classen et al., 2009). While specific information is not readily available for determining the $\mathrm{SF}_{6}$ consumption factor $\left(\mathrm{kg}\left(\mathrm{SF}_{6}\right) / \mathrm{t}(\mathrm{Mg})\right)$ by the Chinese magnesium industry, overall $\mathrm{SF}_{6}$ emissions in China have been increasing sharply and steadily in recent years (Fang et al., 2013a,b).

In response to this state of serious uncertainty, we decided to perform a sensitivity analysis by modifying the database model for $\mathrm{Mg}$ production so as to vary the $\mathrm{SF}_{6}$ emissions as follows:

'no $\mathrm{SF}_{6}$ ' scenario: $0 \mathrm{~kg} / \mathrm{t}$ - assuming the complete world-wide phase-out of $\mathrm{SF}_{6}$;

'low $\mathrm{SF}_{6}$ ' scenario: $1.65 \mathrm{~kg} / \mathrm{t}$ - the mean value from a range of reported factors in the $\mathrm{Mg}$ industry in the Europe, the USA and Japan between 1995 and 2009 (Fang et al., 2013a);

'high $\mathrm{SF}_{6}$ ' scenario: $3.16 \mathrm{~kg} / \mathrm{t}$ - corresponding to the 97.5 percentile of the same range of reported factors (Fang et al., 2013a).

A sensitivity analysis of the EoL treatment scenarios was also performed, similarly to the one described for strategy n. 1 (i.e. 'pessimistic' $=75 \%$ open-loop recycling and 'optimistic' = $90 \%$ close-loop recycling of $\mathrm{Mg}$ parts). In this case, though, the environmental credits associated to open-loop recycling of $\mathrm{Mg}$ parts were computed as arising from the direct 
replacement of the current $\mathrm{Al}$ (not $\mathrm{Mg}$ ) mix. This is because, in the current common practice, the lack of an established dedicated collection route for Mg parts entails that when the latter are recycled, they are re-melted together with the larger bulk of $\mathrm{Al}$ parts, and the $\mathrm{Mg}$ effectively ends up becoming an impurity in the resulting Al alloy (Ehrenberger and Friedrich, 2013). In the optimistic scenario, instead, close-loop recycling is taken to imply the like-forlike 1:1 replacement of virgin $\mathrm{Mg}$.

\subsubsection{Strategies n. 3 (Al + CFRP parts) and n. 4 (Mg + CFRP parts)}

Traditional CFRP is produced using a thermosetting polyester or epoxy resin as the matrix, which is liquid at room temperature, and hardens when cured to hold the structural carbon fibres firmly in place, resulting in a material of high specific stiffness and strength. However, the thermosetting resin, once catalyzed, cannot be remolded or reshaped, making recycling thermoset CFRP extremely difficult. Conversely, thermoplastic CFRP is produced using an aliphatic polymer or a polyamide (nylon) matrix, resulting in a finished material which is characterised by lower fatigue strength but which has increased impact resistance and which may be reformed and reshaped. This greatly simplifies performing impact damage repairs and, theoretically at least, enables easier recycling at the end of life (Yang et al., 2012). Thermoplastic CFRP is already used, for instance, for the painted multi-part outer body panels of the innovative BMW i3 electric vehicle (SAE, 2013), and growing demand for similar applications in future lightweight vehicles is anticipated (Teijin, 2014). Consequently, our choice for lightweighting strategies n. 3 and n. 4 was to employ thermoplastic CFRP exclusively for all non-structural components of the vehicle's body, while relying on metal alloys (respectively $\mathrm{Al}$ and $\mathrm{Mg}$ ) for all other BIW components and for selected chassis parts.

Thermoplastic CFRP production was assumed to take place in the UK using imported CF, and was modelled using recent foreground data from the scientific literature (Witik et al., 2011), combined with database information for CF production in Germany (Thinkstep, 
2015a) and for poly(hexano-6-lactam) (nylon-6) (Ecoinvent, 2010), the latter modified to use the most up-to-date UK grid mix (UK government, 2014b).

Three EoL treatment scenarios were considered for lightweighting strategy n. 3 , and the related assumptions for CFRP were informed by the most recent literature in the field (Witik et al., 2013). In the 'pessimistic' scenario, the decommissioned CFRP parts are assumed to be incinerated with energy recovery, and the environmental credits are computed on the basis of the displacement of electricity and thermal energy produced in a combined cycle power plant running on natural gas; the Al parts are $75 \%$ open-loop recycled, like in the corresponding 'pessimistic' EoL scenario for strategy n. 1. In the intermediate scenario (labelled 'realistic'), only $10 \%$ of the CFRP is incinerated, while $90 \%$ is assumed to be sent to be open-loop recycled, and the recovered carbon fibre ( $\mathrm{rCF}$ ) to replace glass fibre (GF) for less demanding applications, with a mass replacement ratio of $1(\mathrm{GF}): 2.5(\mathrm{rCF})$; in this second scenario, the Al parts are still assumed to be open-loop recycled, but the achieved collection rate is assumed reach $90 \%$ (corresponding to the increased Al recycling rate in the transport sector in the EU27, which however has so far only been achieved in practice for commercial vehicles and trains (IAI, 2006)). Finally, in the 'optimistic' scenario, the CFRP is $10 \%$ incinerated and $90 \%$ close-loop recycled, with the rCF now replacing virgin CF with a mass replacement ratio of $1(\mathrm{CF}): 1.5(\mathrm{rCF})$; the Al parts are also $90 \%$ close-loop recycled, like in the corresponding 'optimistic' EoL scenario for strategy n. 1.

Finally, lightweighting strategy n. 4 (Mg + CFRP) was regarded as being intrinsically optimistic / long-term, and consequently only the combination of the most favourable scenarios was considered (i.e. the 'no $\mathrm{SF}_{6}$ ' scenario for Mg production, and the 'optimistic' scenarios for the EoL of both Mg and CFRP parts, as described respectively for strategies $\mathrm{n}$. 2 and n. 3).

\section{$2.3 \quad$ IMPACT ASSESSMENT}


With regards to life cycle impact assessment (LCIA), the choice was made to focus on those impact categories which were deemed to be the most relevant for the systems under study. In addition to the direct fuel consumption in the use phase, the most critical aspects of the systems under study are the primary energy mixtures used in raw material sourcing and processing, vehicle manufacturing, and EoL recycling, with the associated consequences in terms of depletion of non-renewable energy resources and emissions of greenhouse and acidifying gases; and the metal mining and refining operations, which entail potentially large toxic effects. Consequently, the following metrics of potential environmental impact were selected for discussion:

- $\quad$ Non-Renewable Cumulative Energy Demand (nr-CED), measured in units of primary energy equivalent (MJ PE-eq);

- Global Warming Potential (GWP), measured in units of $\mathrm{kg} \mathrm{CO}_{2}$-eq on a 100-year temporal horizon;

- $\quad$ Acidification Potential (AP), measured in units of $\mathrm{kg} \mathrm{SO}_{2}$-eq;

- Human Toxicity Potential (HTP), measured in units of $\mathrm{kg}$ 1,4-dichlorobenzene (DCB)eq.

The latter three mid-point indicators were computed using the latest characterization factors provided by the Institute of Environmental Sciences (CML) of the University of Leiden, NL (CML, 2013).

Other impact categories were also looked into (including Ozone layer Depletion Potential (ODP), Eutrophication Potential (EP), Photochemical Ozone Creation Potential (POCP), etc.), but the associated results were not conducive to any significant additional insights besides those already apparent on the basis of the selected impact metrics listed above.

Finally, we made the explicit choice to refrain from engaging in any additional (optional) LCIA steps such as normalization and, especially, weighting and grouping, since the latter always entail non-scientific value judgements that would have reduced the robustness and transparency of the results (and are recommended against by ISO for all comparative analyses intended to be disclosed to the public (ISO, 2006b)). 


\section{RESULTS AND DISCUSSION}

Detailed results for the full range of analysed strategies and scenarios, including three variations of driving cycle in the use phase by way of sensitivity analysis, are presented in Figures 1-4. These figures are all presented in a similar format whereby the environmental impacts are broken down along the horizontal axis into five life-cycle phases: materials (including extraction, processing and delivery), manufacturing, use, maintenance and end-oflife, followed by a sixth phase resulting from system expansion (environmental credits). A seventh bar then shows the total (cumulative) impact. As explained in section 2, the environmental credit for each scenario is equal to the impact of the average mix of technologies that is assumed to be displaced as a result of EoL material recycling and energy recovery. The vertical axis shows the magnitude of the impacts, both positive and negative, in terms of either energy (for nr-CED) or emissions (for the remaining impact categories).

In the specific case of lightweighting strategy $\mathrm{n} .2$ based on the use of Mg alloy parts, the GWP results were found to strongly depend on the amounts of $\mathrm{SF}_{6}$ emitted, and the following combinations of $\mathrm{SF}_{6}$ and EoL scenarios were selected as the most representative and interesting to discuss: 'high $\mathrm{SF}_{6}$ ' + 'pessimistic EoL'; 'low SF 6 ' + 'pessimistic EoL'; 'low $\mathrm{SF}_{6}$ ' + 'optimistic EoL'; and finally, 'no SF 6 ' + 'optimistic EoL'.

Figure 1. Non-Renewable Cumulative Energy Demand (nr-CED) results.

(a) Aluminium body and chassis scenarios vs. steel benchmark; (b) magnesium body and chassis scenarios vs. steel benchmark; (c) hybrid CFRP + lightweight metal body and chassis scenarios vs. steel benchmark. 
Interestingly, practically all analysed lightweighting strategies (with the only exception of the 'pessimistic' EoL scenario for strategy n. 2) achieved very similar reductions in the total life-cycle non-renewable energy demand, namely between $-3 \%$ and $-7 \%$. Strategy $n$. 1 (all Al body and chassis) produced the best results overall, never falling below $-5 \%$ even in the 'pessimistic' EoL scenario, and assuming the more conservative fuel consumption. The influence of the EoL scenarios was instead larger on strategy n. 2 (all Mg parts), which achieved -5 to $-6 \%$ in the 'optimistic' EoL case (depending on the assumed use phase fuel consumption), but only managed to barely break even with the benchmark in the 'pessimistic' EoL scenario (i.e., the one more closely matching the actual current practice). In other words, unless an effective large-scale scheme is implemented for the separate collection and close-loop recycling of $\mathrm{Mg}$ parts at the EoL of passenger vehicles, the advantages in terms of reduced energy depletion afforded by the lower kerb mass are completely annulled by the net increase in energy demand for the Mg itself.

Figure 2. Global Warming Potential (GWP) Life Cycle Impact Assessment (LCIA) results. (a) Aluminium body and chassis scenarios vs. steel benchmark; (b) magnesium body and chassis scenarios vs. steel benchmark; (c) hybrid CFRP + lightweight metal body and chassis scenarios vs. steel benchmark.

For lightweighting strategies n. $1(\mathrm{Al})$ and n. $3(\mathrm{Al}+\mathrm{CFRP})$, the results in the GWP category track almost perfectly those in terms of nr-CED. Conversely, dramatic differences, and a very wide range of possible outcomes, are showcased for strategy $n$. 2 , due to the extremely large specific impact of $\mathrm{SF}_{6}$. Only under the most favourable conditions (i.e. assuming a complete phase-out of $\mathrm{SF}_{6}$ worldwide and $90 \%$ close-loop recycling of EoL $\mathrm{Mg}$ parts) does strategy n. 2 achieve a (still modest: -2 to $-4 \%$, again depending on use phase fuel consumption) reduction in its overall GWP vs. the benchmark case. Given the current near-monopoly of primary $\mathrm{Mg}$ by Chinese producers, the reported upwards trend in $\mathrm{SF}_{6}$ 
emissions in China and Asia, and the technical and economic hurdles in establishing a nearperfect close-loop recycling scheme for (still comparatively rare) Mg parts, such reductions do not appear to be very realistic. If instead a more likely mean value for $\mathrm{SF}_{6}$ emissions is used, even achieving close-loop recycling would not be enough to offset the sharp increase in GHG emissions in the Mg production stage, and the overall GWP would increase by $+3 \div$ $+7 \%$ over the benchmark case. The situation for strategy $\mathrm{n} .2$ then becomes quite dramatic under the current practice for EoL Mg parts $(+21 \div+29 \%$ GWP $)$, and even more so if the pessimistic (but not entirely unrealistic) assumption is made that Chinese production actually ranks closer to the top of the range of the reported $\mathrm{SF}_{6}$ emissions in the $\mathrm{Mg}$ industry $(+36 \div$ $+48 \%$ GWP in the 'high $\mathrm{SF}_{6}$ (pess EoL)' scenario). Finally, as explained in section 2.2, lightweighting strategy n. 4 (Mg + CFRP) was regarded as being intrinsically optimistic / long-term, and thus only the results corresponding to the most optimistic combination of assumptions are presented. Even so, the overall achievable improvement in GWP was found to be consistently lower than for strategy $\mathrm{n}$. 3, thereby implying that the use of $\mathrm{Mg}$ instead of Al for the structural parts is not really recommendable, in spite of the additional reduction in kerb mass that it allows.

Figure 3. Acidification Potential (AP) Life Cycle Impact Assessment (LCIA) results.

(a) Aluminium body and chassis scenarios vs. steel benchmark; (b) magnesium body and chassis scenarios vs. steel benchmark; (c) hybrid CFRP + lightweight metal body and chassis scenarios vs. steel benchmark.

Both strategies n. $1(\mathrm{Al})$ and $\mathrm{n} .3(\mathrm{Al}+\mathrm{CFRP})$ consistently result in net reductions in the life-cycle AP of the vehicle, ranging from a modest $-1 \div-2 \%$ in the 'pessimistic' EoL scenarios, to a respectable $-5 \div-6 \%$ in the 'optimistic' EoL case. Instead, strategies n. 2 and n. 4 (both entailing Mg use) never manage to break even, producing respectively $+4 \div+7 \%$ 
and $+2 \div+5 \%$ AP even in the 'optimistic' scenarios. Results for the 'pessimistic' EoL scenario of strategy n. 2 are poor at $+22 \div+29 \%$ AP.

Figure 4. Human Toxicity Potential (HTP) Life Cycle Impact Assessment (LCIA) results. (a) Aluminium body and chassis scenarios vs. steel benchmark; (b) magnesium body and chassis scenarios vs. steel benchmark; (c) hybrid CFRP + lightweight metal body and chassis scenarios vs. steel benchmark.

The analysis of the results for the HTP impact category provides interesting food for thought. Firstly, and contrary to all other previously considered impact categories, when focusing on the potential toxic impacts, the use phase no longer features prominently as the most relevant aspect of a vehicle's life cycle. Instead, raw material sourcing and processing becomes at least one order of magnitude more important, thus confirming that most of the toxicity is likely to ensue from the ore mining and fossil fuel extraction processes. Secondly, the pivotal role of EoL recycling is rendered even more apparent than in the other categories. Even taking into account the larger degree of inherent uncertainty in the HTP characterization factors vs. those for the other impact categories, especially for metals (TNO, 2004), the scale of the results is such that the general trend is impossible to ignore.

The situation is particularly severe in the case of Al, the HTP associated to its extraction and processing being so high that close-loop recycling ('optimistic' EoL scenario) becomes a necessity in order for strategy $\mathrm{n} .1$ to break even with the benchmark. In the current situation (75\% open-loop recycling, corresponding to the 'pessimistic' EoL scenario), relying on $\mathrm{Al}$ parts to reduce the kerb mass of the vehicle actually results in $+33 \div+40 \%$ increase in overall HTP (depending on the variable possible contribution of the use phase). The influence of $\mathrm{Al}$ is felt on strategy n. 3 too, where a break-even with the benchmark is only reached in the intermediate ('realistic') EoL scenario, while the current situation ('pessimistic' scenario, corresponding to open-loop recycling for $\mathrm{Al}$ and incineration for CFRP) results in 
up to $+21 \%$ HTP. A better result (approximately $-13 \%$ ) is achieved in the 'optimistic' EoL scenario (in which both the Al and the CF are assumed to be close-loop recycled). The seemingly anomalous results for strategy n. 2 (the 'pessimistic' EoL scenario producing more favourable results than the 'optimistic' one) is explained by noting that when $\mathrm{Mg}$ parts are open-loop recycled, they end up displacing $\mathrm{Al}$ in its alloys, thereby achieving a larger 'environmental credit' in terms of HTP than when they are close-loop recycled, and displacing Mg itself (which has a lower HTP to begin with). Thus, HTP results for strategy $n$. 2 range from $-20 \%$ to a remarkable $-49 \%$. Finally, HTP results for the analysed 'optimistic' scenario for strategy n. 4 are good at $-20 \div-22 \%$, benefiting from both close-loop recycling and the lack of Al.

An intrinsic source of variability in all LCAs resides in the unavoidable reliance on average industry data for the background processes (Huijberts, 1998; Heijungs and Huijberts, 2004). Although the Ecoinvent database does provide uncertainty information for some of its datasets (Dones et al., 2005), this is by no means comprehensive, and a complete and statistically rigorous quantification of the overall uncertainty associated with $\mathrm{LCl}$ data is often still virtually impossible to obtain in most cases (Shannon et al., 2007). A further layer of uncertainty is then due to the complex and uncertain nature of many environmental processes, and to the often imperfect models used to estimate the potential environmental impact associated to the system's emission flows.

In the light of all this, it is important to always keep in mind that the results of all comparative LCAs, including the one presented here, are always to be interpreted primarily as indicative of the relative ranking of the analysed alternatives, and should not be expected to be characterised by a high degree of precision, which in most cases remains unattainable. It is however self-evident that, ceteris paribus, the robustness of the results is considerably improved when it can be shown that the order of preference of the alternatives is not affected by a sensitivity analysis performed on a range of key parameters at the level of the foreground inventory. 
In fact, the results of our analysis were found to be quite robust in terms of the assumed mass reductions for the lightweight parts vs. their steel counterparts (cf. section 2.2). A sensitivity analysis (not reported here for the sake of conciseness) showed that even large relative deviations of $+/-10 \%$ in the assumed mass reductions (e.g. varying the mass reductions in the range from $-45 \%$ to $-55 \%$ for $\mathrm{Al}$ parts) would produce only minor differences in the results (e.g. a $+/-1 \%$ relative difference in the GWP results in the case of $\mathrm{Al})$.

Also, and perhaps contrary to what might have been expected, the sensitivity analysis on the fuel consumption in the use phase did not produce large enough changes in the overall results to subvert the order of preference of the lightweighting strategies. This reinforces the importance of carrying out fully fledged LCAs, especially when dealing with less conventional products such as lightweight vehicles employing advanced materials, for which received (and often over-simplistic) 'rules of thumb' no longer apply.

Conversely, the results, and even their relative ranking, may and do change (sometimes dramatically, as in the case of the GWP in strategy n. 2, and indeed the HTP in all strategies) when expanding the scope of the analysis beyond the use phase to the full life cycle of the vehicle.

Results were also found to be critically dependent on a number of key modelling assumptions (e.g. modelling of the vehicle's combined fuel consumption vs. only the massinduced share thereof, EoL scenarios, etc.) and parameter values (e.g. total distance travelled, type and extent of power train adaptation). We argue that in order for the results to be meaningful, such choices should be made in strict adherence to the intended goal of the study (i.e. so as to be as representative as possible of the actual operational, geographic and temporal conditions for which answers are sought), and be consistently applied across the board of the alternative strategies being compared.

\section{CONCLUSIONS}


Overall, the use of $\mathrm{Al}$ parts in lightweighting strategy n. 2 has produced the most consistent set of results, not requiring any ad hoc optimistic assumptions in order to deliver them and showing the least dramatic dependence on the EoL scenarios. The only remarkable exception to this general trend is represented by the HTP results, which need careful consideration, and which indicate that a 'simple' clear-cut answer in terms of "which strategy is best" may actually not exist, when different (and irreducible) impact categories are considered.

The life-cycle environmental performance of Mg parts in strategy $\mathrm{n}$. 2 does not appear to provide a convincing argument for their use in lieu of their less expensive and only marginally heavier Al counterparts. In fact, the criticality of the $\mathrm{SF}_{6}$ issue, together with the relative impracticality of requiring separate close-loop recycling schemes for $\mathrm{Mg}$ and $\mathrm{Al}$, tend to suggest that strategy n. 2 may actually end up performing considerably worse than strategy n. 1 in real-world conditions.

From an environmental point of view, the use of thermoplastic CFRP parts in strategies $n$. 3 and n.4 appears to produce reasonably good results overall; the fact that the results are not significantly better than those for strategy $n$. 1, though, may seriously question the effectiveness of strategies n. 3 and n. 4 from the point of view of the extent of the environmental benefit achieved per unit of economic investment.

Last but not least, our analysis seems to clearly indicate that it is probably unreasonable to expect any primary lightweighting strategy, when taken in isolation, to be capable of reducing the nr-CED, GWP, or AP of the full life cycle of a compact passenger vehicle by more than $\sim 7 \%$ at most.

This last point in particular shows that far more paradigmatic changes in the entire structure and organization of the transport system, and ultimately possibly of our daily lives, than just reducing vehicle mass by a few kilograms, are required to solve the environmental problems of personal mobility.

\section{ACKNOWLEDGMENTS}


The authors wish to acknowledge the financial support provided by the UK Engineering and Physical Sciences Research Council, under research grant EP/I038616/1 "Towards Affordable, Closed-Loop Recyclable Future Low Carbon Vehicle Structures - TARF-LCV”. Thanks are also due to Charles Kingdom, formerly at Coventry University, for his collaboration in the definition of the body part masses for the benchmark vehicle.

\section{REFERENCES}

Aluminium Federation, 2013. UK Aluminium Industry Fact Sheet 5: Aluminium Recycling. http://www.alfed.org.uk/downloads/documents/B80E71BI66_5_aluminium_recycling.pdf

Audi, 2013.

http://www.audi.com/com/brand/en/vorsprung_durch_technik/content/2013/08/light-isgood.html

Bala Gala A., Raugei M., Fullana-i-Palmer P., 2015. Introducing a new method for calculating the environmental credits of end-of-life material recovery in attributional LCA. Int. J. Life Cycle Assess. DOI: 10.1007/s11367-015-0861-3.

BMW, 2015.

http://www.bmw.com/com/en/insights/technology/efficientdynamics/phase_2/technology/light weight_construction.html

Borken-Kleefeld J., Fuglestvedt J., Berntsen T., 2013. Mode, Load, And Specific Climate Impact from Passenger Trips. Environ. Sci. Technol 47, 7608-7614.

Classen M., Althaus H.-J., Blaser S., Tuchsmid M., Jungbluth N., Doka G., Faist Emmenegger M., Scharnhorst W., 2009. Life Cycle Inventories of Metals; Final Report ecoinvent data v2.1, No 10.. www.ecoinvent.org.

CML, 2013. CML Life Cycle Impact Assessment method (CML-IA). Institute of Environmental Sciences, University of Leiden, 2013. http://cml.leiden.edu/software/data-cmlia.html. 
Consoli F., Allen D., Boustead I., de Oude N., Fava J., Franklin R., Jensen A.A., Parrish R., Perriman R., Postlethwaite D., Quay B., Séguin J., Vigon B. (Eds), 1993. Guidelines for LifeCycle Assessment: a "Code of Practice". SETAC.

Das S., 2011. Life cycle assessment of carbon fiber-reinforced polymer composites. Int. J. Life Cycle Assess. 16, 268-282.

Das S., 2014. Life Cycle Energy and Environmental Assessment of Aluminum-Intensive Vehicle Design. SAE Int. J. Mat. Manuf. 7(3), 588-595.

DG Environment, 2009. Service contract to assess the feasibility of options to reduce emissions of $\mathrm{SF}_{6}$ from the EU non-ferrous metal industry and analyse their potential impacts; Report to the European Commission. http://ec.europa.eu/clima/policies/fgas/docs/report_sf6_en.pdf

Directive 2000/53/EC of the European Parliament and of the Council, 2006; http://eurlex.europa.eu/legal-content/EN/TXT/?uri=CELEX:32000L0053

Dones R., Heck T., Faist Emmernegger M., Jungbluth N., 2005. Life cycle inventories for the nuclear and natural gas energy systems, and examples of uncertainty analysis. Int. J. Life Cycle Assess. 10(1):10-23.

Du J., Han W., Peng Y., 2010. Life Cycle Greenhouse Gases, Energy and Cost Assessment of Automobiles Using Magnesium from Chinese Pidgeon Process. J. Cleaner Prod. 18, $112-119$

Du J., Han W., Peng Y., 2010. Life cycle greenhouse gases, energy and cost assessment of automobiles using magnesium from Chinese Pidgeon process. J. Cleaner Prod. 18, 112119.

Duflou J.R., De Moor J., Verpoest I., Dewulf W., 2009. Environmental impact analysis of composite use in car manufacturing. CIRP Ann. Manuf. Technol. 58, 9-12. 
Eckstein L., Göbbels R., Wohlecker R., 2011. Benchmarking of the electric vehicle Mitsubishi i-MiEV. ATZ autotechnology 11, 26-33.

Ecoinvent Centre for Life Cycle inventories (Ecoinvent), 2010. Ecoinvent LCI database version 2.2. http://www.ecoinvent.org/database/.

Ecometrica, 2008. Consequential and Attributional Approaches to LCA: a Guide to Policy Makers with Specific Reference to Greenhouse Gas LCA of Biofuels; Technical Report.. http://ecometrica.com/assets/approachesto_LCA3_technical.pdf.

Ehrenberger S., Friedrich H.E., 2013. Life-Cycle Assessment of the Recycling of Magnesium Vehicle Components. JOM 65 (10), 1303-1309.

European Aluminium Association (EAA), 2013. Aluminium in Cars. Unlocking the Lightweighting Potential. http://www.alueurope.eu/wp-content/uploads/2013/10/EAA-Aluminiumin-Cars-Unlocking-the-light-weighting-potential_September2013_03.pdf.

Fang X., Hu X., Janssens-Maenhout G., Wu J., Han J., Su S., Zhang J., Hu J., 2013a. Sulfur Hexafluoride $\left(\mathrm{SF}_{6}\right)$ Emission Estimates for China: An Inventory for 1990-2010 and a Projection to 2020. Environ. Sci. Technol. 47, 3848-3855.

Fang X., Thompson R.L. Saito T., Yokouchi Y., Kim J., Li S., Kim K.R., Park S., Graziosi F., Stohl A., 2013b. Sulfur hexafluoride $\left(\mathrm{SF}_{6}\right)$ emissions in East Asia determined by inverse modelling. Atmos. Chem. Phys. Discuss. 13, 21003-21040.

Ford, 2014. https://media.ford.com/content/fordmedia/fna/us/en/news/2014/06/03/fordbuilds-on-advanced-materials-use-with-lightweight-concept.html.

Gaines, L. and R. Cuenca. 2002. Operation of an aluminum-intensive vehicle: Report on a six year project. Technical Paper No. 2002-01-2066. Warrendale, PA: Society of Automotive Engineers (SAE). 
Gossan Resources, 2012. Lowering of $\mathrm{CO}_{2}$ Emission for Magnesium Production by Gossan-Zuliani Process. www.gossan.ca/projects/pdf/MgGHGReport.pdf.

Huijberts M.A.J., 1998. Application of uncertainty and variability in LCA. Part I. A general framework for the analysis of uncertainty and variability in life cycle assessment. Int. J. Life Cycle Assess. 3(5):273-280.

Heijungs R., Huijberts MAJ, 2004. A review of approaches to treat uncertainty in LCA. Proceedings of the IEMSS conference, Osnabruck (D).

Intergovernmental Panel on Climate Change (IPCC), 2007. Climate Change 2007: Working Group I: The Physical Science Basis.

http://www.ipcc.ch/publications_and_data/ar4/wg1/en/ch2s2-10-2.html.

International Aluminium Institute (IAI), 2006. Aluminium Recycling in Europe - The Road to High Quality Products. http://www.world-

aluminium.org/media/filer_public/2013/01/15/fl0000217.pdf.

International Aluminium Institute (IAI), 2009. Global Aluminium Recycling: A Cornerstone of Sustainable Development. http://www.world-

aluminium.org/media/filer_public/2013/01/15/fl0000181.pdf.

International Council on Clean Transportation (ICCT), 2013. European Vehicle Market Statistics - Pocketbook 2013. http://www.theicct.org/european-vehicle-market-statistics2013.

International Magnesium Association (IMA), 2013. Life Cycle Assessment of Magnesium Components in Vehicle Construction.

http://www.intlmag.org/pdfs/reports/111913_lca_report_public.pdf.

International Organization for Standardization (ISO), 2006a. 14040 - Environmental Management. Life Cycle Assessment. Principles and Framework.. 
International Organization for Standardization (ISO), 2006b. 14044 - Environmental Management. Life Cycle Assessment. Requirements and Guidelines.

JLR, 2015. http://www.jaguarlandrover.com/gl/en/innovation/world-leaders-in-aluminium/.

Joint Research Centre (JRC) - Institute of Environment and Sustainability, European Commission, 2010. ILCD Handbook: General guide for Life Cycle Assessment: detailed guidance. http://lct.jrc.ec.europa.eu/pdf-directory/ILCD-Handbook-General-guide-for-LCADETAIL-online-12March2010.pdf.

Kim H.C., Wallington T.J., 2013. Life-Cycle Energy and Greenhouse Gas Emission Benefits of Lightweighting in Automobiles: Review and Harmonization. Environ. Sci. Technol. 47, 6089-6097.

Kim H.-J., McMillan C., Keoleian G.A., Skerlos S.J., 2010. Greenhouse Gas Emissions Payback for Lightweighted Vehicles Using Aluminum and High-Strength Steel. Journal of Industrial Ecology, 14(6):929-946.

Koffler C., 2014. Life cycle assessment of automotive lightweighting through polymers under US boundary conditions. Int. J. Life Cycle Assess. 19, 538-545.

Koffler C., Rhode-Brandenburger K., 2010. On the calculation of fuel savings through lightweight design in automotive life cycle assessments. Int. J. Life Cycle Assess. 15, 128135.

Liu G., Müller D.B., 2012. Addressing sustainability in the aluminium industry: a critical review of life cycle assessments. J. Cleaner Prod. 35, 108-117.

Mayyas A.T., Qattawi A., Mayyas A.R., Omar M.A., 2012. Life cycle assessment-based selection for a sustainable lightweight body-in-white. Energy 39, 412-425. 
Mock P., German J., Bandivadekar A., Riemersma I., 2012. Discrepancies between typeapproval and "real-world" fuel-consumption and $\mathrm{CO}_{2}$ values. The International Council on Clean Transportation.

http://www.theicct.org/sites/default/files/publications/ICCT_EU_fuelconsumption2_workingpa per_2012.pdf

Mock P., Kühlwein J., Tietge U., Franco V., Bandivadekar A., German J., 2014. The WLTP: How a new test procedure for cars will affect fuel consumption values in the EU. The International Council on Clean Transportation.

http://www.theicct.org/sites/default/files/publications/ICCT_WLTP_EffectEU_20141029.pdf

Thinkstep, 2015a. GaBi LCl database. http://www.gabi-software.com/databases/gabidatabases/.

Thinkstep, 2015b. GaBi software. http://www.gabi-software.com/software/gabi-software/.

Regulation (EC) No 842/2006 of the European Parliament and of the Council, 2006. http://eur-lex.europa.eu/LexUriServ/LexUriServ.do?uri=OJ:L:2006:161:0001:0011:EN:PDF.

Rohde-Brandenburger K., 1996. Verfahren zur einfachen und sicheren Abschätzung von Kraftstoffverbrauchspotenzialen. In Einfluss von Gesamtfahrzeug-Parametern auf Fahrverhalten/Fahrleistung und Kraftstoffverbrauch conference proceedings; Haus der Technik Essen, Germany.

Rohde-Brandenburger K., Obernolte J., 2008. CO2-Potential durch Leichtbau im Pkw, DVMTag 2008—Leichtbaustrategien. Deutscher Verband für Materialforschung und -prüfung e.V; Berlin, Germany.

Schmidt W-P., Dahlqvist E., Finkbeiner M., Krinke S., Lazzari S., Oschmann D., Pichon S., Thiel C., 2004. Life Cycle Assessment of Lightweight and End-of-Life Scenarios for Generic Compact Class Passenger Vehicles. Int. J. Life Cycle Assess. 9 (6), 406-416. 
Schnoor J.L., 2009. LCA and Environmental Intelligence? Environ. Sci. Technol. 43 (9), 2997-2997.

Shannon M. L., Ries R., 2007. Characterizing, propagating, and analyzing uncertainty in Life-Cycle Assessment. A survey of quantitative approaches. J. Ind Ecol. 11(1):161-181.

Society of Automotive Engineers (SAE), 2013. http://articles.sae.org/12056/

Suzuki T., Takahashi J., 2005. LCA of Lightweight Vehicles by Using CFRP for massproduced vehicles. $15^{\text {th }}$ International Conference on Composite Materials, Durban, South Africa. http://j-t.o.oo7.jp/publications/050627TS.pdf

Teijin, 2014. http://www.teijin.com/rd/technology/cfrp/

Tharumarajah A., Koltum P., 2007. Is there an environmental advantage of using magnesium components for light-weighting cars? J. Cleaner Prod. 15, 1007-1013.

TNO, 2004. Improvement of LCA characterization factors and LCA practice for metals. TNOReport R 2004/347, Apeldoorn, NL.

http://media.leidenuniv.nl/legacy/final\%20report\%20metals.pdf.

UK Government, 2014a. Official statistics: provisional UK greenhouse gas emissions. https://www.gov.uk/government/publications/provisional-uk-emissions-estimates.

UK Government, 2014b. Electricity statistics. https://www.gov.uk/government/collections/electricity-statistics.

United States Department of Energy (US-DoE), 2015.

http://energy.gov/eere/vehicles/vehicle-technologies-office-lightweight-materials-cars-andtrucks.

United States Energy Information Administration (US-EIA), 2014.

http://www.eia.gov/countries/cab.cfm?fips=CH. 
United States Environmental Protection Agency (US-EPA), 2014.

http://www.epa.gov/magnesium-sf6/.

United States Geological Survey (USGS), 2014. Magnesium Statistics and Information. http://minerals.er.usgs.gov/minerals/pubs/commodity/magnesium/mcs-2014-mgmet.pdf.

Witik R.A., Payet J., Michaud V., Ludwig C., Månson J-A., 2011. Assessing the life cycle costs and environmental performance of lightweight materials in automobile applications. Composites: Part A 42, 1694-1709.

Witik R.A., Teuscher R., Michaud V., Ludwig C., Månson J-A., 2013. Carbon fibre reinforced composite waste: An environmental assessment of recycling, energy recovery and landfilling. Composites: Part A 49, 89-99.

Wohlecker, R., M. Johannaber, and M. Espig. 2007. Determination of weight elasticity of fuel economy for ICE, hybrid and fuel cell vehicles. Paper No. 2007- 01-0343. Warrendale, PA: Society of Automobile Engineers (SAE).

Yang Y., Boom R., Irion B., van Heerden D.-J., Kuiper P., de Wit H., 2012. Recycling of composite materials. Chem. Eng. Process. 51, 53-68. 


\section{Supplementary Information}

A Coherent Life Cycle Assessment of a Range of Lightweighting Strategies for Compact Vehicles

Marco Raugei*, Denise Morrey, Allan Hutchinson, Patricia Winfield

Faculty of Technology, Design and Environment, Oxford Brookes University, Wheatley Campus, Wheatley OX33 1HX, UK

${ }^{*}$ Corresponding author. E-mail: marco.raugei@brookes.ac.uk

Supplementary Information includes:

1) the bill of materials of vehicle body and chassis for all analysed lightweighting strategies;

2) a full list of the acronyms used. 


\section{BILL OF MATERIALS OF VEHICLE BODY AND CHASSIS}

\begin{tabular}{|c|c|c|c|c|c|c|c|c|c|c|}
\hline \multirow[b]{2}{*}{ Body part } & \multicolumn{2}{|c|}{ Benchmark } & \multicolumn{2}{|c|}{ Strategy 1} & \multicolumn{2}{|c|}{ Strategy 2} & \multicolumn{2}{|c|}{ Strategy 3} & \multicolumn{2}{|c|}{ Strategy 4} \\
\hline & material & $\mathrm{kg}$ & material & $\mathrm{kg}$ & material & $\mathrm{kg}$ & material & $\mathrm{kg}$ & material & $\mathrm{kg}$ \\
\hline floor-pan & steel & 64 & Al & 32 & Mg & 25 & CFRP & 19 & CFRP & 19 \\
\hline cross-beam & steel & 6.3 & Al & 3.2 & Mg & 2.5 & Al & 3.2 & Mg & 2.5 \\
\hline A-pillars & steel & 21 & Al & 10 & Mg & 8.3 & Al & 10 & Mg & 8.3 \\
\hline B-pillars & steel & 8.1 & Al & 4.0 & Mg & 3.2 & Al & 4.0 & Mg & 3.2 \\
\hline doors & steel & 36 & Al & 18 & Mg & 14 & CFRP & 11 & CFRP & 11 \\
\hline bonnet & steel & 17 & Al & 8.3 & Mg & 6.6 & CFRP & 5.0 & CFRP & 5.0 \\
\hline boot & steel & 5.3 & Al & 2.6 & Mg & 2.1 & CFRP & 1.6 & CFRP & 1.6 \\
\hline exterior & steel & 54 & Al & 27 & Mg & 22 & CFRP & 16 & CFRP & 16 \\
\hline $\begin{array}{c}\text { structural } \\
\text { components }\end{array}$ & steel & 70 & Al & 35 & Mg & 28 & Al & 35 & $\mathbf{M g}$ & 28 \\
\hline brackets & steel & 0.60 & Al & 0.32 & Mg & 0.26 & Al & 0.32 & Mg & 0.26 \\
\hline glazing & glass & 66 & glass & 66 & glass & 66 & glass & 66 & glass & 66 \\
\hline acoustics & $\begin{array}{c}\text { PP } \\
+ \text { felt } \\
\end{array}$ & 3.8 & $\begin{array}{c}\text { PP } \\
+ \text { felt }\end{array}$ & 3.8 & $\begin{array}{r}\text { PP } \\
+ \text { felt } \\
\end{array}$ & 3.8 & $\begin{array}{r}\text { PP } \\
+ \text { felt } \\
\end{array}$ & 3.8 & $\begin{array}{c}\text { PP } \\
+ \text { felt } \\
\end{array}$ & 3.8 \\
\hline Chassis part & material & $\mathrm{kg}$ & material & $\mathrm{kg}$ & material & $\mathrm{kg}$ & material & $\mathrm{kg}$ & material & $\mathrm{kg}$ \\
\hline front axle & steel & 41 & Al & 21 & Mg & 14 & Al & 21 & Mg & 14 \\
\hline rear axle & steel & 28 & Al & 14 & Mg & 9.4 & Al & 14 & Mg & 9.4 \\
\hline breaking system & steel & 35 & steel & 35 & steel & 35 & steel & 35 & steel & 35 \\
\hline steering system & steel & 12 & steel & 12 & steel & 12 & steel & 12 & steel & 12 \\
\hline wheels & Al & 25 & $\mathrm{Al}$ & 25 & $\mathrm{Al}$ & 25 & $\mathrm{Al}$ & 25 & $\mathrm{Al}$ & 25 \\
\hline tyres & $\begin{array}{l}\text { rubber } \\
+ \text { steel }\end{array}$ & 25 & rubber & 25 & rubber & 25 & rubber & 25 & rubber & 25 \\
\hline
\end{tabular}

Table S1. Bill of Materials of vehicle body and chassis for all analysed lightweighting strategies. 


\section{ACRONYMS}

\begin{tabular}{ll} 
AP & Acidification Potential \\
BIW & Body in White \\
CF & Carbon Fibre \\
rCF & recycled Carbon Fibre \\
CFRP & Carbon Fibre Reinforced Polymer \\
nr-CED & Non-Renewable Cumulative Energy Demand \\
$\mathrm{CO}_{2}$ & Carbon dioxide \\
DCB & 1,4-dicholrobenzene \\
EoL & End of Life \\
EU27 & European Union, enlarged to 27 member states in the year 2007 \\
GF & Glass Fibre \\
GHG & Greenhouse Gas \\
GWP & Global Warming Potential \\
HSS & High-Strength Steel \\
HTP & Human Toxicity Potential \\
LCA & Life Cycle Analysis \\
LCl & Life Cycle Inventory \\
LCIA & Life Cycle Impact Assessment \\
NEDC & New European Driving Cycle \\
SE & Primary Energy \\
SO & Sulphur hexafluoride \\
& Sulphur dioxide \\
\hline
\end{tabular}

